\title{
0 processo criativo, a arquitetura e o design na vivência da experiência Refúgio Criativo
}

Miguel Canãs Martins (Currículo Lattes) Marli Teresinha Everling (Currículo Lattes)

\section{INTRODUÇÃO}

Ao longo da reflexão conduzida sob a forma de dissertação (realizada noâmbito doPrograma demestrado profissionalem Design/ PPGDesign da Univille) os processos criativos e o papel da imersão', a subjetividade do usuário e as interseções metodológicas entre as

\footnotetext{
1 Segundo Viana (2012), trata-se da etapa em que a equipe de projeto se aproxima com mais profundidade do contexto do problema, tanto do ponto de vista do cliente como do usuário final. Destaca-se que, embora Viana aborde a imersão ao discorrer sobre design thinking, nesta dissertação esta associação não é compulsória pela percepção, que boa parte das abordagens de Design, em maior ou menor escala, também fazem uso dessa etapa mesmo que utilizando outras nomenclaturas.
} 
áreas de Arquitetura e Design estiveram no centro do processo. A discussão teve como objeto a análise da prática profissional adotada pelo escritório de arquitetura Metroquadrado, do qual Miguel Cañas (autor da dissertação) é sócio. Por esse envolvimento, pela escolha de situar as equipes e as pessoas envolvidas no estudo no centro do processo e em respeito a coautoria dos participantes, o relato será realizado na primeira pessoa do plural.

O objetivo central da experiência foi discutir os processos criativos nas áreas de Design e Arquitetura e suas interseções, considerando aspectos de imersão e de experiência para projetos de arquitetura (especialmente o contexto da Metroquadrado). Para isso, caracterizamos o escritório; abordamos conceitos associados à criatividade e a experiência em um contexto de arquitetura-arte; identificamos possibilidades de aproximação entre Arquitetura e Design, abrangendo arquitetura no contexto de atuação da Metroquadrado; realizamos experiências e atividades imersivas no âmbito interno do escritório e no âmbito externo, exercitando a interdisciplinaridade; e, por fim, abordamos as repercussões da discussão teórica e das atividades prático-imersivas nos projetos desenvolvidos com clientes ao longo desta discussão e, na sexta etapa, discutimos possibilidades futuras.

Destacamos que neste relato pretendemos abordar sobretudo as experiências e atividades imersivas conduzidas sob a forma de workshop envolvendo arquitetos, designers e profissionais de outras áreas com o intuito de proporcionar o compartilhamento de experiências pessoais/profissionais e o desenvolvimento de um trabalho coletivo com foco na atividade de projetar. Essa escolha deriva do significado que a experiência teve para a trajetória da dissertação e do sentido que assumiu para os participantes. 


\section{CONTEXTUALIZANDO A EXPERIÊNCIA: O INÍCIO DE TUDO}

O percurso preliminar que conduziu ao Refúgio Criativo envolveu, em um primeiro momento, a caracterização do escritório Metroquadrado, considerando a localização e o histórico da empresa, seu posicionamento, sua atuação, áreas de interesse e relevância da discussão sobre identidade; em seguida, conduzimos um breve panorama sobre conceitos de criatividade e experiência no âmbito deste projeto, abordando, num primeiro momento, a importância desse tema no contexto da Metroquadrado.

Posteriormente, discutimos as ações de criatividade da Metroquadradoeos processoscriativosdaempresaàluzdaabordagem de autores como Watson (2013), Ostrower (2013), Naccache (2013), Medeiros (2004), Cross (2004) e Gomes (2001) e discorremos sobre a noção de experiência em uma abordagem que aproxima arquitetura e arte com base no pensamento de Dornburg (2002), Pallasma (2005) e Abellán (2014); esses autores discutem características mais dinâmicas, multifuncionais e mutantes para a arquitetura, visando proporcionar diferentes dimensões da experiência humana ao apontar um novo paradigma da área, que leva em conta os sentidos e o corpo. Também apresentamos conceitos e possibilidades de aproximação entre design e arquitetura; abordamos, principalmente com base em Edson Mahfuz (2003, 2013, 2014) e Ciro Pirondi (2014), os diversos componentes que caracterizam a arquitetura e que fazem essa disciplina transitar ao mesmo tempo por áreas como engenharia e arte, razão pela qual a história da humanidade teve tanta dificuldade em precisar seu significado. Apresentamos também algumas definições sobre processos metodológicos para projetos de Arquitetura, mais intensamente na visão de Biselli (2011), Segawa (2014), Kahn (1991) e Lemos (2003), acrescentando na sequência 
o processo de atuação da Metroquadrado, considerando equipe, processos e trabalho e detalhamento das etapas de projeto. Logo após, refletimos acerca de possíveis contribuições do Design em procedimentos de Arquitetura no processo de trabalho do escritório Metroquadrado, considerando as abordagens de Sanders (2005, 2008, 2010), Cross (2004), Maurício Viana et al. (2012) e Brown (2010). Procuramos refletir sobre como podemos projetar experiências e acessar emoções do usuário e abordamos a sua participação no processo, questionando como alcançar anseios subjetivos do cliente/ usuário; em seguida, abordamos afinidades entre arquitetura e design no contexto do escritório Metroquadrado. Na sequência, concluímos com a observação de interseções percebidas entre as duas áreas e o processo do escritório, novamente a partir de Tim Brown (2010), Maurício Viana et al. (2012) e Nigel Cross (2004).

Após esse percurso, planejamos, vivenciamos e discutimos as práticas imersivas para a exploração das afinidades entre Arquitetura e Design no contexto da Metroquadrado e para além dele. Esta abordagem abrange a preparação, condução e desdobramentos do Refúgio Criativo (workshop destinado à experimentação interdisciplinar dos processos associados, especialmente, à Arquitetura e Design) e dos três workshops internos conduzidos com a equipe da empresa. Destacamos que doravante o relato abordará com maior intensidade as atividades relacionadas ao Refúgio Criativo. 


\section{A PREPARAÇÃO DO REFÚGIO CRIATIVO}

Em virtude do interesse latente do escritório Metroquadrado na área do Design, há um movimento de aproximação com profissionais dessa área, sobretudo, com a equipe do escritório de design Firmorama (descrito em seu site como escritório de design e estúdio criativo); essa proximidade é o desdobramento do relacionamento interpessoal entre os sócios das duas empresas que se conheceram, passaram a trocar referências e a se reencontrar em atividades de interesse comum.

A intensificação do convívio entre as duas equipes originou um movimento apelidado de 'Metrorama' (junção de nomes Metroquadrado e Firmorama), que tem como ideia central intensificar a interdisciplinaridade das duas áreas na atuação das duas empresas. As afinidades e os diálogos constantes sobre os processos de trabalhos de cada empresa transformaram-se em indicações de trabalho de ambos os lados no intuito de apresentar aos clientes a oportunidade de se desenvolver um projeto mais abrangente ao oferecer arquitetura e design juntos.

A partir da percepção das coincidências na forma de pensar decidiram evidenciar com mais ênfase o suporte que uma área poderia dar à outra. No entanto, mais do que um trabalho complementar, o maior interesse estava em elaborar uma forma de trabalho diferente do que vinham fazendo. $O$ primeiro encontro que selou essas intenções foi realizado no dia 2 de outubro de 2014. A síntese redigida a partir desse encontro pode ser assim expressa: utilizar princípios de design de experiência para aliar arquitetura e identidade, posicionamento e criação no envolvimento do negócio dos clientes em etapas de descobertas anteriores ao briefing, construir o briefing com o cliente, ter liberdade experimental e atuar 
como curadores de informação. Estava claro que pretendíamos uma abordagem centrada em pessoas e seus anseios. Projetar para marcas fundamentou-se sobre o mesmo pressuposto: em se reconhecendo a essência da marca revela-se um propósito que a torna pessoal.

Ressaltamos que até esse momento o autor desta dissertação estava mais inclinado ao desenvolvimento de uma proposta metodológica sistematizada e mais orientada para sua própria atuação apesar de já haver um forte interesse pelas etapas iniciais de imersão/preparação para o projeto. A partir desse encontro o foco da dissertação deixou de ser pessoal e assumiu um caráter mais voltado para a atuação coletiva da equipe Metroquadrado e passou a contar com a sua participação por meio de workshops, reuniões e conversas informais. Esse encontro também foi decisivo para concepção e preparação do Refúgio Criativo.

Planejamos o Refúgio Criativo como um workshop orientado para atividade prático-criativa-imersiva, com o intuito de proporcionar dois momentos distintos (ambos interessados nos processos criativos de cada participante/empresa): o compartilhamento e depoimentos individuais e o desenvolvimento de um trabalho coletivo, sendo este projetar uma cabana. Pretendíamos com isso ampliar o campo de visão dos participantes de modo a favorecer o trabalho individual de cada um ao discutir procedimentos que fazem parte das práticas de trabalho dos profissionais envolvidos (contribuindo para a intersecção entre as áreas).

O workshop foi planejado para ocorrer em dois dias e foi agendado para os dias 29 e 30 de novembro de 2014, tendo a natureza e os espaços ao ar livre como cenário em uma chácara localizada em Blumenau/SC. A Metroquadrado e a Firmorama, representadas pelos sócios Miguel Cañas Martins e Jackson Peixer, formaram uma comissão organizadora responsável por desenhar e conduzir o 
workshop, sua estratégia, conteúdo, cronograma de atividades e identidade. Como mediadores, isso incluiu organizar e discutir cada momento, etapa ou ação realizada durante o fim de semana, bem como planejar o workshop na fase preliminar cuidando de cada detalhe; esse planejamento teve início em setembro de 2014.

A criação do roteiro do workshop também foi colaborativa. $O$ trabalho em conjunto utilizou de ferramentas online, permitindo que os líderes criassem e editassem documentos simultaneamente, colaborando em tempo real. Essas ferramentas facilitaram o desenvolvimento das fases do workshop, como descrever o roteiro, discutir a lista de materiais ou atribuir tarefas. Além disso, discussões sobre logística e necessidades, como uso de barracas, lanternas, repelentes, também foram abordadas.

No intuito de proporcionar uma imersão aprofundada e exercitar o foco dos participantes para que a experiência fosse a mais completa possível, discutimos bastante sobre a geração de conteúdo, de imagens e vídeos que o workshop geraria. Portanto, cada detalhe do processo deveria ser pensado não só por sua experiência de uso, mas como uma expressão estética.

Embora o roteiro tenha sido criado com recurso de planejamento e organização das ações e atividades conduzidas ao longo do workshop, foi considerado desde o início que não se tratava de uma experiência com procedimentos fechados. Era preciso que a equipe tivesse liberdade para adequar-se ao contexto de acordo com seus objetivos. Deveria haver espaço para o improviso. O tom da conversa deveria ser o mais informal, livre e espontâneo possível.

A fase de preparação para workshop também previu algumas tarefas para todos os participantes: (1) cada empresa deveria enviar sua marca e um release de apresentação; (2) cada pessoa enviaria duas imagens que fossem representativas para si (o objetivo disso 
era surpresa e seria apresentado no dia do workshop); (3) cada participante levaria um artefato que era importante para si ou que carregasse uma história interessante para ser compartilhada com o grupo todo; (4) cada um levaria o material que acredita que seja interessante compartilhar com todos, referências impressas, livros, anotações e tudo que puder servir de base para que construíssemos em conjunto as discussões.

Em termos mais subjetivos pretendíamos proporcionar espaços para o silêncio, a experimentação e a contemplação, no intuito de promover uma entrega total e em profundidade. Queríamos criar um espaço favorável para atividades prático-criativas e de autoconhecimento. Esses objetivos definiram o nome do workshop: Refúgio Criativo.

Em termos mais objetivos, o Refúgio Criativo foi planejado para ser uma pausa no espaço-tempo cotidiano e privilegiar o projeto coletivo (com a participação de designers e arquitetos). Pretendia proporcionar o exercício do olhar e o pensamento reflexivo, explorando o processo projetual de forma mais experimental, no intuito de potencializar a experiência das pessoas na paisagem, como um artefato-manifesto que transcendesse o conceito de espaço físico: de um lugar para estar a um momento para sentir.

Para orientar as atividades, uma série de temáticas pertinentes aos processos de trabalho de cada um foi considerada; incluímos no planejamento uma etapa para abordagem de: desempenhos profissionais, design autoral, trabalhos colaborativos, valores sociais, liberdade, tempo, foco, riscos, medos, inovação, tradicionalismo etc. Ou seja, reflexões sobre modelos alternativos, correlações e novas possibilidades de aprendizados por meio do depoimento dos outros.

O planejamento e a realização do refúgio envolveu cinco empresas de áreas distintas e complementares, localizadas na 
região norte do estado de Santa Catarina: a Vasselai, construtora de Blumenau; a Firmorama, estúdio de design gráfico e ilustração de Jaraguá do Sul; a Metroquadrado, escritório de arquitetura de Joinville; e o estúdio de fotografia e vídeo Entremonte, de Jaraguá do Sul. Além disso, um profissional externo, o terapeuta e designer Luis Fernando Leier, foi convidado a participar das atividades compilando as informações debatidas.

Apesar do compartilhamento de diversas informações entre todos os participantes do refúgio nas semanas que antecederam o workshop, muitos detalhes só foram compartilhados entre os organizadores. Isso incluía o próprio roteiro de atividades e experiências que seriam proporcionadas. Entre as surpresas estavam a escolha do cardápio de cada refeição que seria servida (café da manhã, almoço e janta), a seleção da trilha sonora que serviria de música ambiente durante as atividades e a entrega de um kit de desenho (Figura 1).

Figura 1 - Materiais de apoio desenvolvidos para o Refúgio Criativo
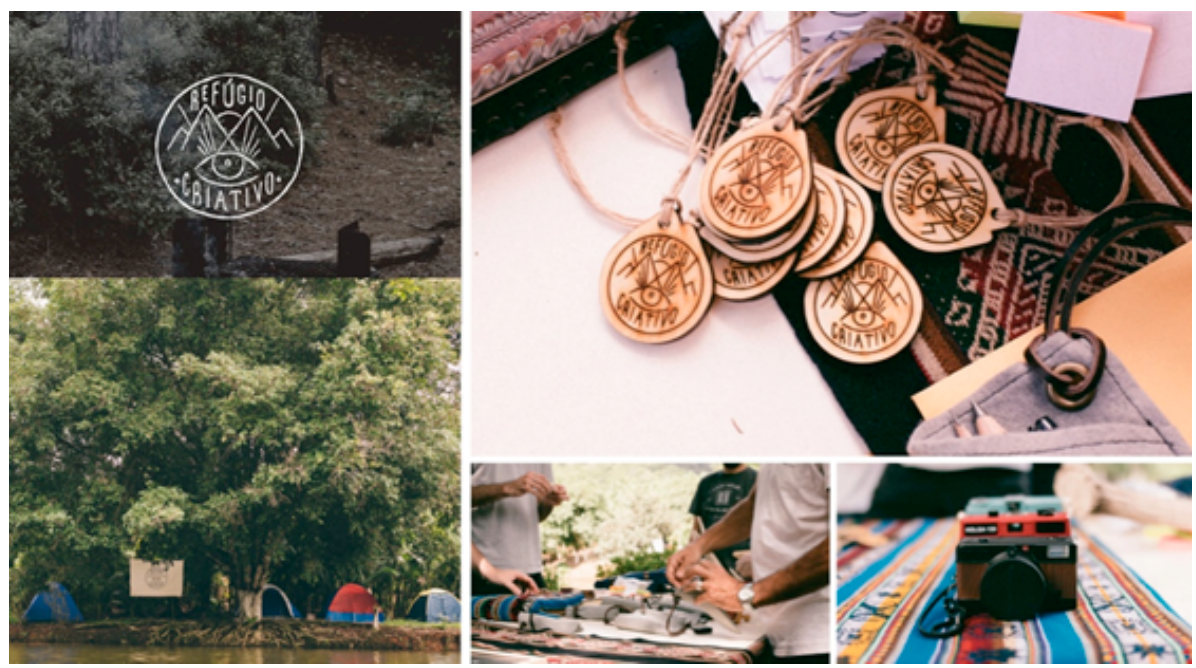

Fonte: Entremonte (Estúdio de fotografia e vídeo) 
O kit foi composto de um estojo de feltro e couro, desenhado especialmente para o refúgio, composto de canetas, lápis e borracha, bem como um caderno personalizado de desenho e anotações contendo o manifesto do Refúgio, o nome das empresas, as fotos que cada participante havia enviado anteriormente e a marca criada para o Refúgio Criativo, além de outras páginas impressas com elementos gráficos, fotos, textos e desenhos. Carimbos com a marca do Refúgio Criativo, adesivos e canecas de alumínio personalizadas também compunham os materiais entregues a cada participante. Por último, cada um recebeu um pequeno banco de madeira, executado especialmente para o refúgio, que serviu de apoio para as atividades realizadas em meio a natureza.

Por se tratar de uma experiência imersiva projetada para exercitar a atenção, o foco e o distanciamento das distrações e pensamentos do dia a dia, utilizamos essencialmente apenas meios analógicos de desenho e comunicação. Portanto, recomendamos que não fossem levados computadores, laptops e telefones celulares para o refúgio.

\section{Durante o primeiro dia...}

No primeiro dia o Refúgio Criativo teve seis momentos bem definidos, que foram: descompressão, autoconhecimento, lanche, temáticas/oficinas do futuro, alimentação \& depoimento, fogueira \& celebração.

A descompressão. O sábado pela manhã foi o período da chegada de todos. Foi um momento de informalidade, destinando a provocar um respiro e relaxamento, promovendo o distanciamento da rotina do dia anterior de cada participante. Foi o momento de observação, reconhecimento do terreno por meio de caminhadas, conversas informais entre os participantes, familiarização com as 
ferramentas de trabalho e tecnologias disponíveis e instalação do acampamento (Figura 2), entre outras atividades.

Figura 2 - localização do acampamento Refúgio Criativo

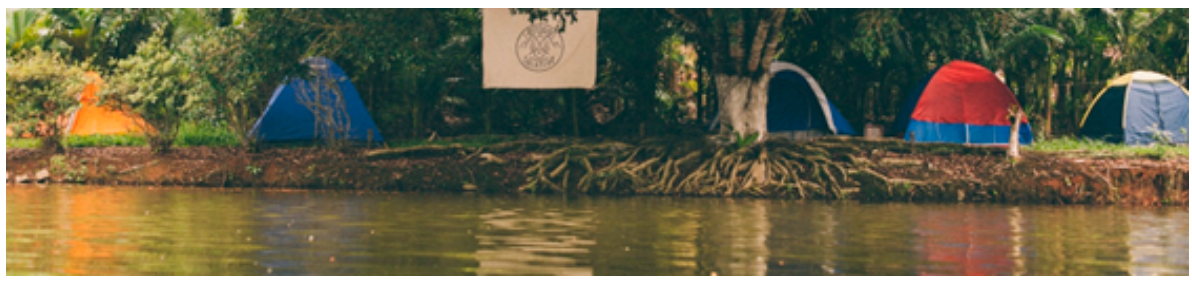

Fonte: Entremonte (estúdio de fotografia e vídeo)

Ao redor de uma mesa ao ar livre, organizamos todo material levado para o refúgio; montamos, de forma participativa, os kits surpresa para cada participante (Figura 3). Foi um momento que gerou, já desde o começo, uma atmosfera de cumplicidade e empatia.

Figura 3 - organização dos Kits de apoio

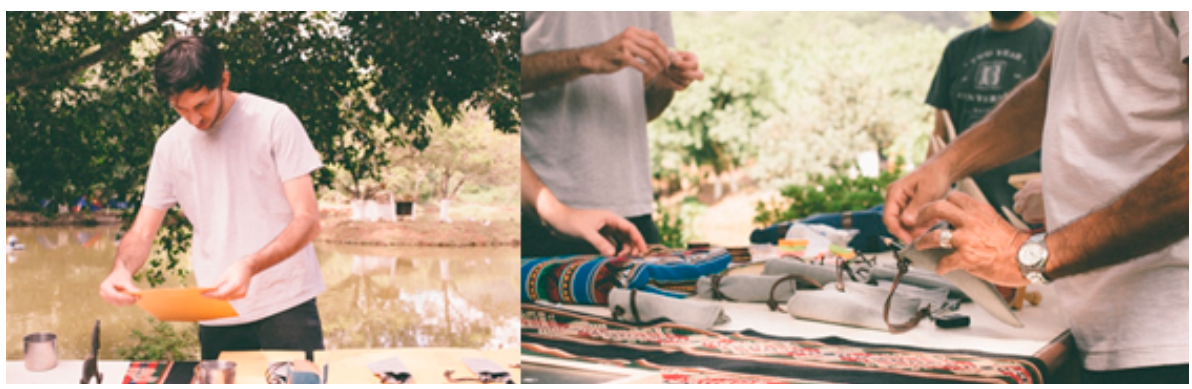

Fonte: Entremonte (estúdio de fotografia e vídeo)

O autoconhecimento. De posse dos kits personalizados, nos dirigimos a outra área do terreno. Trabalhar em lugares diferentes do terreno para cada atividade foi importante para dar contraste aos momentos, facilitado a identificação do começo e término de uma ação e a colaboração intensificando o envolvimento em cada experiência (essa atividade possibilitou reconhecer possibilidades do 
terreno). Sentados em círculo nos bancos de madeira no meio de um bambuzal, abrimos a experiência apresentando o projeto do Refúgio e seu propósito (Figura 4).

Figura 4 - atividade relacionada ao momento 2

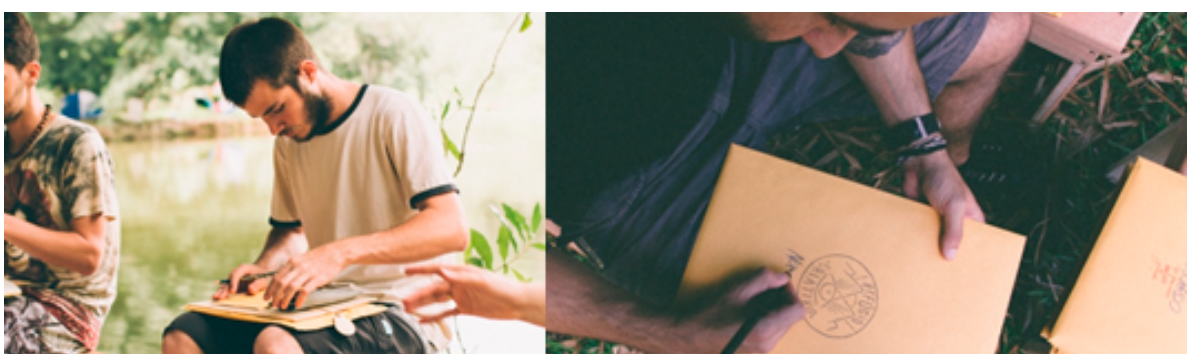

Fonte: Entremonte (estúdio de fotografia e vídeo)

De forma a tornar o momento o mais especial e íntimo possível, para que pudesse proporcionar uma entrega maior de cada participante, transformamos o momento em uma espécie de ritual, no qual utilizamos um 'bastão que fala' (baseado em tradições indígenas, aquele que detém o bastão tem a oportunidade de apresentar uma ideia enquanto os demais escutam, favorecendo as decisões democráticas, de maneira justa e imparcial).

De posse do bastão, o participante apresentava-se de forma livre, tendo como sequência o compartilhamento do seu artefato pessoal especial e o que foi chamado de 'exercício do choque'. Ao descrever um objeto especial para si, a pessoa, intuitivamente, começa a falar de si própria. Esse momento foi fundamental para que se criasse uma noção de grupo e de propósito, fundamentalmente necessários para uma melhor experiência durante o Refúgio Criativo, proporcionando uma maior entrega, fluidez e abertura no diálogo do grupo.

O lanche. Após do diálogo de autoconhecimento, realizamos um intervalo, no qual todos se dirigiram a outra área do terreno 
e compartilharam uma mesa com frutas e sucos. O objetivo era respirar e descontrair a conversa, proporcionando um momento de pausa após a etapa de apresentação, tendo em vista que muitos depoimentos foram intensos e emocionaram a todos. Destacamos a experiência estética de apresentação da alimentação, nos materiais dos utensílios e na forma como foram elaborados os pratos (Figura 5).

Figura 5 - apresentação da mesa
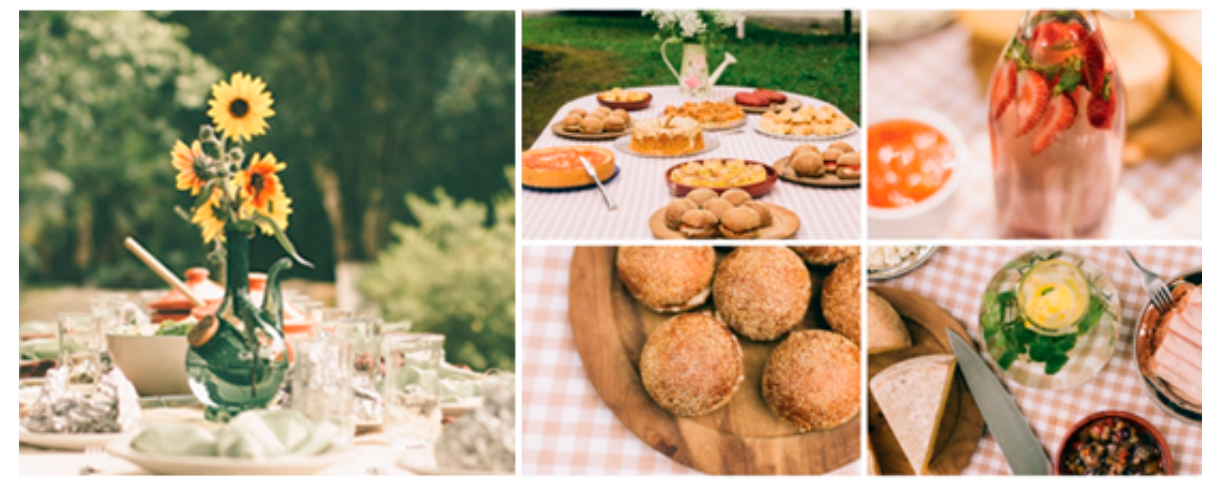

Fonte: Entremonte (estúdio de fotografia e vídeo)

Temáticas / oficina do futuro. O momento das temáticas talvez tenha sido um dos mais importantes do primeiro dia, devido à intensa troca de informações. Escolhemos um local confortável, sob uma árvore, de forma que todos pudessem sentar-se no chão e apoiarse para fazer anotações. O diálogo começou de forma livre, tendo dois dos participantes como mediadores (Miguel e Jackson), com a intenção de desenvolver e conversar sobre uma série de assuntos a partir de uma pergunta, como uma provocação inicial: 'considerando seu processo criativo, ferramentas de imersão, vivências pessoais, como você relaciona todo seu movimento pessoal e profissional com a ideia desse retiro imersivo?'. Esse compartilhamento permitiu que os participantes aprendessem com a experiência do outro; 
com os depoimentos individuais foi possível internalizar alguns pontos, refletindo sobre usos alternativos, correlações nas formas de trabalho e novas possibilidades de aprendizagem. Compartilhamos reflexões individuais acerca dos processos criativos, metodologias e ferramentas, desafios pessoais e profissionais, visão de mundo, valores, medos e futuro (Figura 6).

Figura 6 - Informações geradas no momento 4
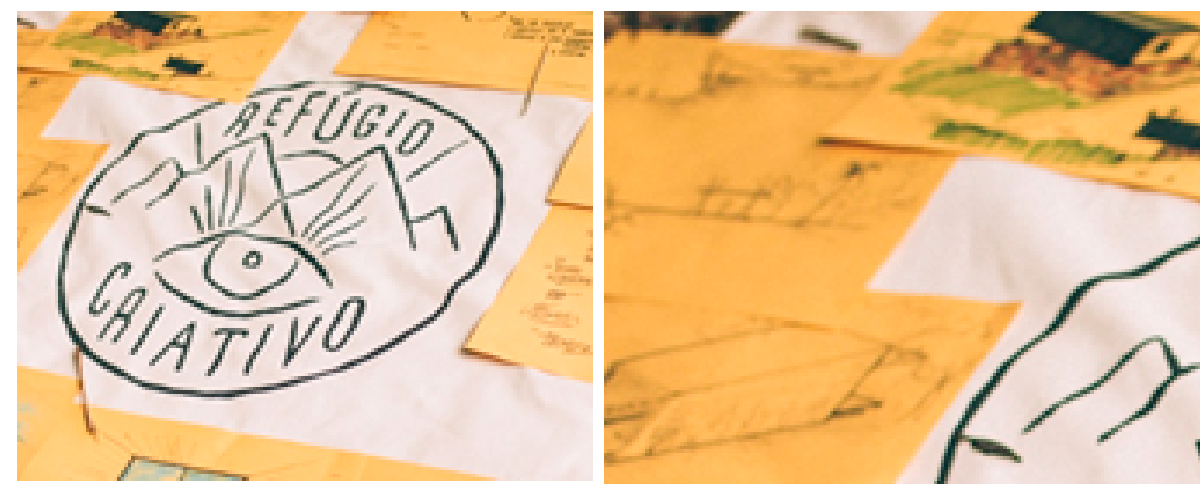

Fonte: Entremonte (estúdio de fotografia e vídeo)

O objetivo nesse momento foi exercitar o foco, dialogar abertamente sobre os processos criativos de cada um e observar pontos de concordância e divergência em cada realidade e área de trabalho, pois vindos de universos diferentes estaríamos iniciando o pensamento sobre um projeto colaborativo, aprendendo em conjunto, de maneira livre, expondo pensamentos.

Organizamos a oficina de trabalho para que os colaboradores discutissem suas experiências de vida e de trabalho (seus processos criativos e desafios) utilizando as tecnologias disponíveis no acampamento: depoimentos de experiências e sensações vividas (imagens e palavras para mostrar uma experiência relacionada a algo em seu passado), contação de histórias e leitura de textos, desenho à mão livre etc. Desse momento destacamos algumas palavras- 
chave, como: tempo escasso (no sentido do período de concepção dedicado aos projetos de cada empresa), linguagem expressiva (discussão entre ferramentas analógicas e digitais) e experiências imersivas (reconhecimento da relevância de experiências como o Refúgio Criativo para exercício do foco nos processos individuais).

Alimentação e depoimento. Logo após o momento das temáticas houve uma pausa para uma alimentação. No meio da tarde de sábado, a refeição caracterizou-se como um café colonial, com uma variedade grande de opções. Novamente o cenário foi outro, ainda inexplorado. Em conjunto, escolhemos o local para o café e o posicionamento da mesa comunitária para tal. Optamos pela acomodação próxima a uma antiga construção enxaimel localizada em uma colina do terreno. A atmosfera e o cenário contribuíram para uma conversa descontraída, na qual os assuntos permeavam o universo discutido nas temáticas, mas de uma forma mais descompromissada.

Ao término da refeição, ainda sentados à mesa, ocorreu um momento de depoimento pessoal. O designer Luís Fernando Leier relatou sua experiência com o universo da meditação e como isso influencia seu processo de trabalho. Leier desenha mandalas, que o colocam em contato com alguma esfera da criação, trazendo assim autoconhecimento e uma compreensão melhor a respeito do universo que o rodeia.

Naquele momento, o designer ampliou a discussão sobre os processos criativos, agregando um ingrediente mais holístico ao abordar temas do comportamento mental no processo criativo. Leier trouxe à discussão assuntos relacionados com expansão da consciência, pensamento, energia, conceitos sobre o tempo e o efêmero, criatividade e foco. Para ele, por meio da meditação é possível desenvolver a habilidade de ouvir a consciência, de observar seus 
pensamentos e sentimentos e expressar os sentidos, aprendendo a identificar e discernir o que é ego e o que é consciência e contribuindo para a autopercepção e a ação nas atividades do dia a dia. Em sua atividade, essa descoberta é traduzida sobre uma forma de desenho, que são as mandalas, que por sua vez são a tradução de um propósito. Ou seja, trata de direcionar energia, para que o pensamento organize essa energia e a manifeste em forma (desenho).

Leier também abordou a meditação e exercícios de respiração no nível da experiência como meio de relaxar o corpo e a mente para possibilitar o aprofundamento na nossa própria estrutura psicofísica e a descobrir novas dimensões internas que são canalizadas no ato de desenhar.

Fogueira e celebração. Já no fim do dia, foi realizado em outra parte do terreno, numa clareira, em um dos pontos mais altos do local. Em colaboração, procuramos a madeira necessária para a construção da fogueira e nos organizamos em forma de círculo ao redor do fogo.

Oato da fogueira foi um momento de interiorização do conteúdo exposto durante o dia todo. Foi um momento mais individual, de mais silêncio e pouco diálogo, de absorção e assimilação de tudo que foi conversado, de juntar os pontos que até o momento estavam se conectando e fazendo sentido para cada um (Figura 7). Mergulhar em tanta informação até aquele momento foi fundamental para organizar o pensamento para a tarefa do dia seguinte: projetar em conjunto um artefato arquitetônico. 
Figura 7 - A fogueira

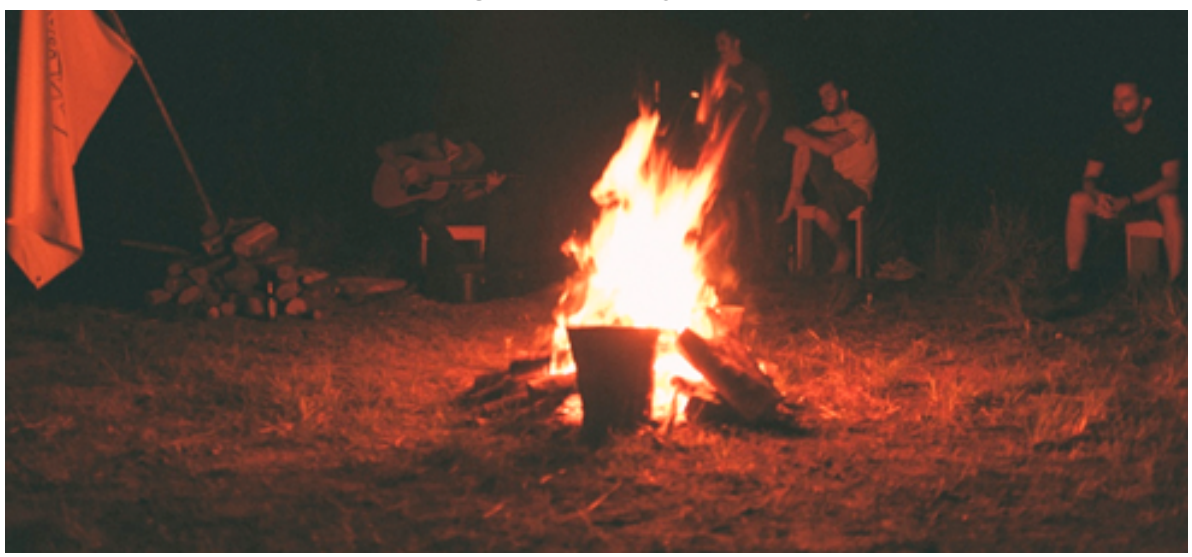

Fonte: Entremonte (estúdio de fotografia e vídeo)

A música ambiente permeou essa atividade, com uma trilha sonora mais experimental e meditativa, auxiliando na introspecção individual do participante. Horas mais tarde, ainda ao redor da fogueira, a trilha sonora deu lugar à participação de uma pequena apresentação ao vivo do músico Williard Ribeiro, com voz e violão. A essa altura um clima de celebração já começava a tomar forma, culminando, após a apresentação de Ribeiro, na preparação do jantar, no qual todos puderam auxiliar, de forma prática, na preparação do alimento, transformando mais uma vez o ato numa oportunidade para uma experiência sensorial única. Fim do primeiro dia.

\section{E no segundo dia...}

No segundo dia o Refúgio Criativo teve cinco momentos bem definidos que foram: oficina de coexploração, caminhada cognitivaexploratória e definição do lugar, almoço, prototipação e conclusão.

Oficina de coexploração. O segundo dia foi dedicado à ideação e prototipagem (aqui compreendida como atividade que se apoia em códigos gráficos para exploração, síntese e modelação verbal e 
gráfica do conceito) da cabana do Refúgio Criativo. Sentados ao redor de uma mesa ao ar livre, e com as ferramentas de trabalho expostas, iniciamos a troca de ideias e reflexões (Figura 8).

Figura 8 - Oficina de coexploração

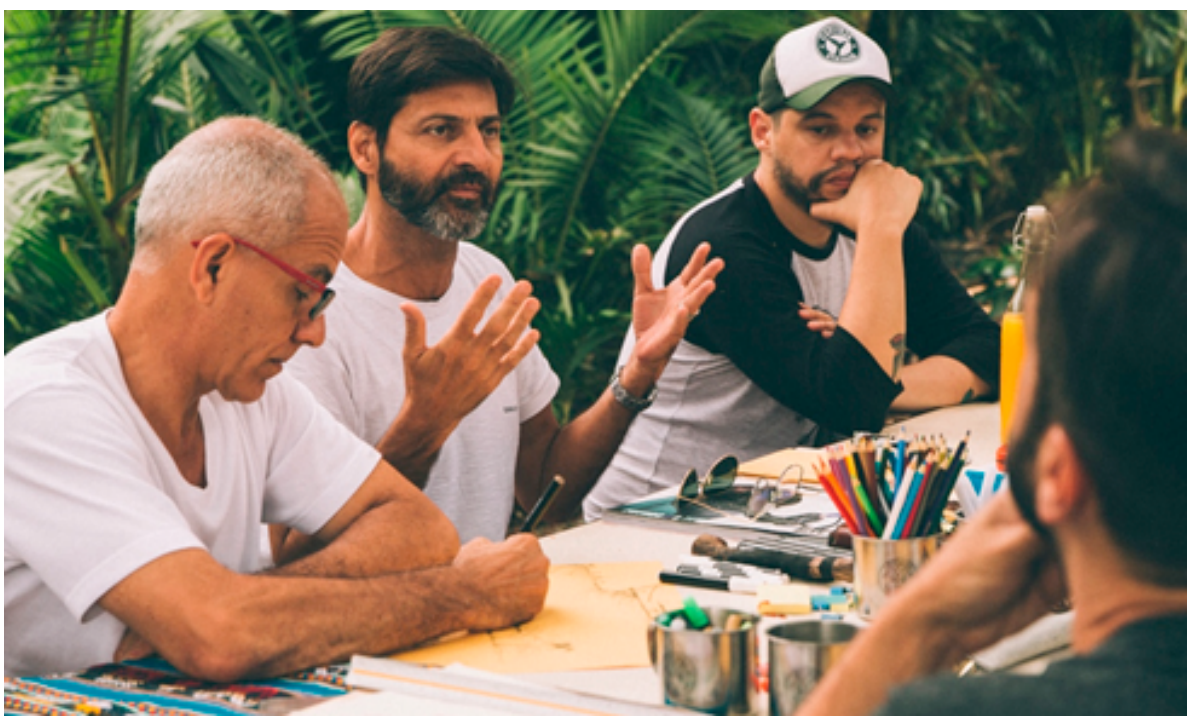

Fonte: Entremonte (estúdio de fotografia e vídeo)

Embora não se tenha pré-determinado de forma rígida uma ferramenta de trabalho para a atividade de grupo, a forma natural como o momento foi sendo conduzido levou para uma discussão mais orgânica e flexível, em que havia espaço para o inesperado e o imprevisível. Sendo assim, a utilização das técnicas de brainstorming e mapas mentais pareceram ser as mais adequadas, pois desenvolvemos naturalmente um fluxo livre de troca de ideias, de forma solta, imaginativa e sem limites ou censura, definindo associações, percepções e compreensões por meio de tentativa e erro. As ideias foram agrupadas para uma análise, crítica e viabilidade (Figura 9). 
Figura 9 - Oficina de coexploração
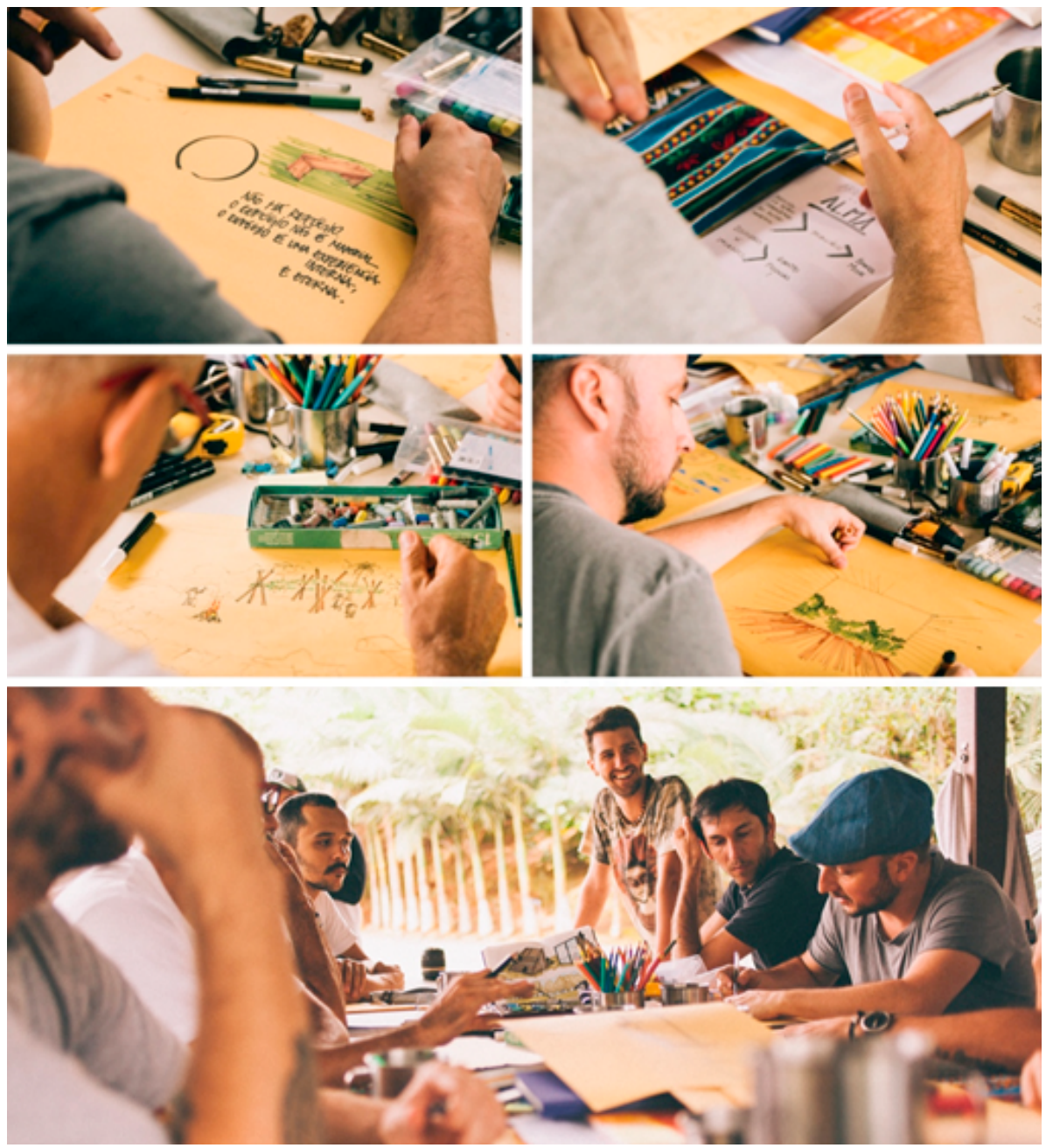

Fonte: Entremonte (estúdio de fotografia e vídeo)

Utilizamos basicamente o desenho à mão livre, ferramentas diversas de desenho (marcadores, lápis, giz pastel, etc.), leitura de textos e exploração de painéis semânticos/moodboards com imagens de inspiração, que permeavam trabalhos de arte, instalação, design e arquitetura (Figura 10). Os desenhos e os textos criavam aos poucos uma narrativa que trazia à discussão momentos de sessões 
de interpretação para perguntas como: o que é o Refúgio Criativo e o que ele significa para cada um? Quais são os objetivos do Refúgio Criativo? e quais são as necessidades do Refúgio Criativo? Que forma ele deve ter? Discutimos o problema e elencamos cenários de uso futuro (após executada a cabana) que foram sendo definidos. Destacamos os 'achados', aspectos perceptivos e atitudinais, visando etapas posteriores (figura 10).

Figura 10 - Sínteses gráficas e materiais utilizados na oficina de coexporação

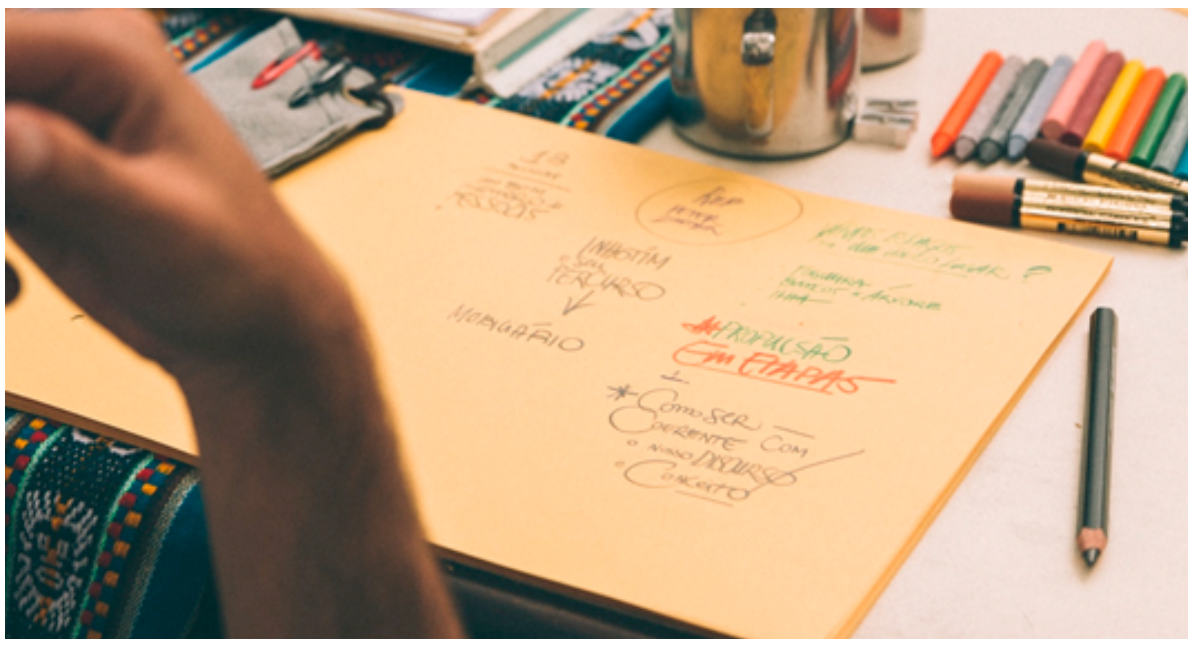

Fonte: Entremonte (estúdio de fotografia e vídeo)

Dessa discussão extraímos informações que podiam auxiliar na geração de soluções projetuais, considerando: a forma pela qual as pessoas vão utilizar o refúgio, o ambiente físico, o contexto de uso e emoção, percepções, valores estéticos, aspectos culturais.

Após a discussão sobre o tema, separamos algumas informações que foram agrupadas em categorias (uso, materiais, técnicas etc.) que possibilitaram o estabelecimento de relações entre conceitos e seu posterior refinamento; por último, foi realizada a triagem e conclusão (avaliação, proposição de soluções e síntese dos resultados). 
Essa atividade estendeu-se até o momento em que se alcançou um resultado de acordo com as necessidades e os objetivos. 0 conceito gerado como síntese levou em conta aspectos técnicos (materiais, técnicas construtivas, viabilidade financeira), aspectos funcionais (como seria a relação das pessoas no espaço) e aspectos estéticos (a forma da cabana).

Figura 11 - Croquis da geração de alternativas para o espaço Refúgio Criativo

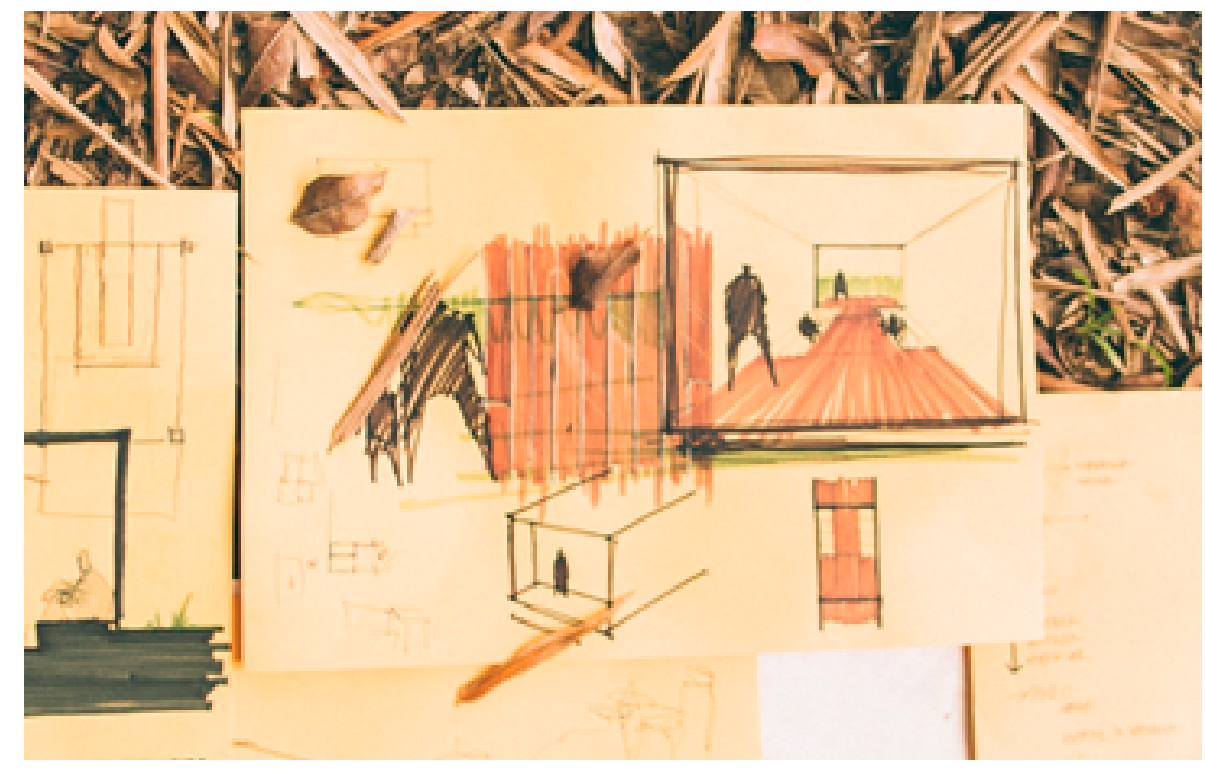

Fonte: Entremonte (estúdio de fotografia e vídeo)

Entre os resultados desse momento destacamos: (1) pensamento orientado para soluções criativas; (2) conhecer as opiniões dos envolvidos e determinar uma visão consensual do grupo sobre as questões discutidas (organização, estruturação, categorização, resumo e hierarquização dos dados qualitativos e pensamentos): (3) estabelecer relação com os conceitos levantados durante as observações ao longo dos dois dias do workshop Refúgio Criativo. 
Caminhada cognitivo-exploratória e definição do lugar. Após uma primeira rodada de discussão e levantamento de alguns pontos partimos para a segunda caminhada pelo terreno (Figura 12), a fim de reconhecer melhor o local para construção do refúgio, produzindo novos subsídios para o projeto, como implantação, orientação, estratégias visuais, topografia, insolação, ventos dominantes, relação com entorno e acesso ao local. Ou seja, itens intrínsecos à definição de um partido arquitetônico, que, entretanto, no desenvolvimento deste trabalho, ficou em segundo plano. Verificamos aqui que o processo e abordagem interdisciplinar na conceituação do projeto foi mais importante que alguns dos aspectos de discussão de um partido arquitetônico, como a situação da obra no terreno.

Figura 12 - Caminhada cognitivo-exploratória pelo terreno

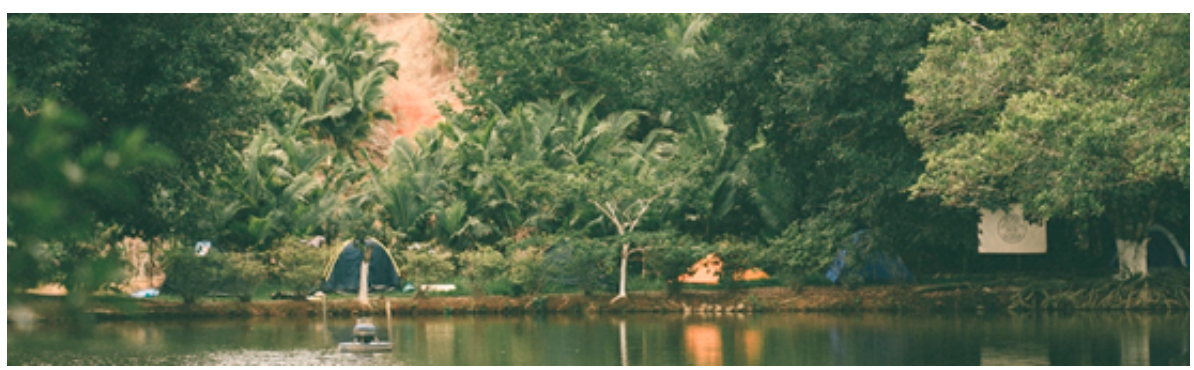

Fonte: Entremonte (estúdio de fotografia e vídeo)

Almoço. A pausa para o almoço foi estratégica para dar um certo distanciamento do tema e digerir os pontos que conseguimos elencar até aquele momento. Sentados novamente ao redor de uma mesa comunitária ao ar livre, conversamos de forma mais amena sobre as descobertas e surpresas a que havia se chegado.

Prototipação. Após o almoço, foi o momento para validação e refinamento das ideias e sinapses produzidas, do que foi discutido, materializado e desenhado nas fases de ideação. A mesa comunitária 
foi utilizada como base para de trabalho e suporte de materiais para 'desenhar' em conjunto o que seria o Refúgio Criativo, avaliando os painéis semânticos/moodboards, rascunhos, desenhos, maquetes e tudo o que foi considerado interessante materializar por meio do processo de cada um (Figura 13). Havia uma preocupação importante com uma mesa grande, onde todos pudessem trabalhar juntos e não separados em grupos.

Figura 13 - Resultado do momento da prototipação

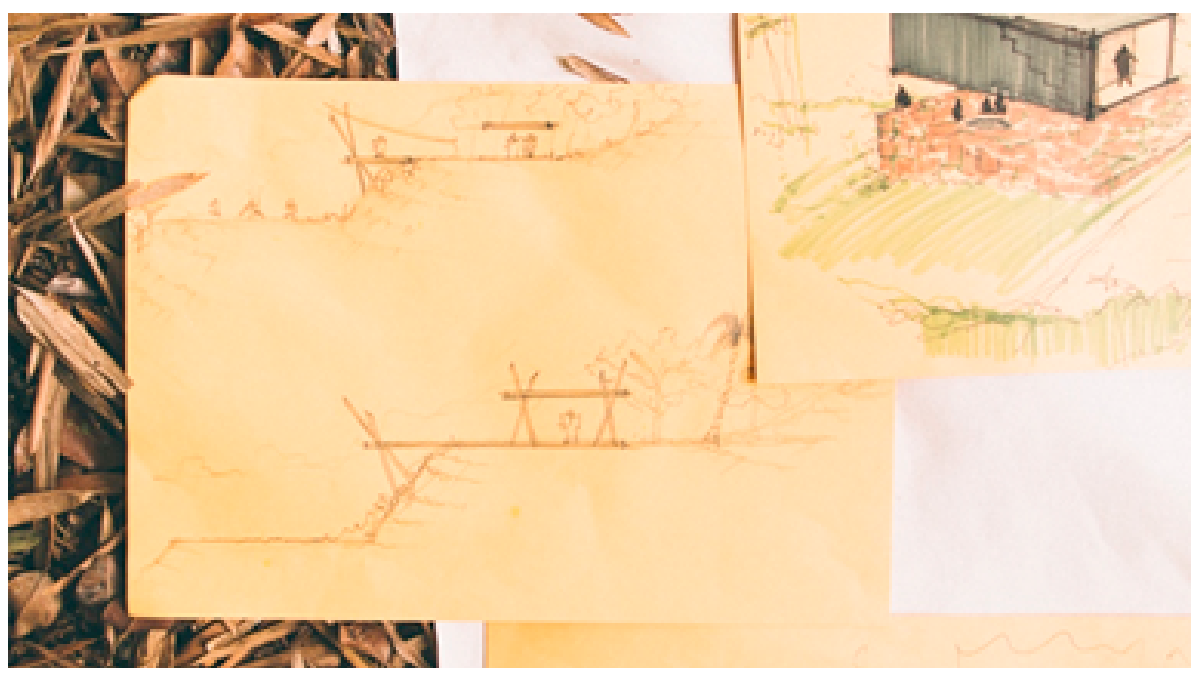

Fonte: Entremonte (estúdio de fotografia e vídeo)

Fechamento. No fim da tarde do segundo dia, sentados novamente em roda, próximos ao bambuzal e utilizando os bancos individuais, aconteceu a conclusão desse processo prático, com a discussão de possíveis caminhos com o Refúgio, ou seja, dentro de todas as opções, que rumos o projeto poderia seguir. Para isso foi organizado um painel semântico/moodboard com os caminhos mais interessante e foram elencadas tarefas importantes a serem realizadas como, próximos passos entre cada participante ou empresa, como 
por exemplo, detalhamento do projeto executivo de arquitetura e memorial descritivo do projeto, orçamento da obra, decupagem dos registros de imagens e vídeos, relação das anotações de cada participante realizadas ao longo do workshop e refletir sobre os desdobramentos (objetivos e subjetivos) futuros.

O fechamento do Refúgio Criativo ocorreu com o compartilhamento do que foi a experiência, em um panorama geral, para cada participante e com o estabelecimento dos próximos passos, considerando cronograma e planejamento dos materiais de comunicação da experiência projetual do Refúgio Criativo.

\section{DESDOBRAMENTOS SUBJETIVOS E OBJETIVOS E REFLEXOS DA EXPERIÊNCIA}

A reflexão produzida durante o Refúgio Criativo permitiu mergulhar mais profundamente nos próprios pensamentos (confrontando-os ao mesmo tempo com os demais participantes) e, o ato de acompanhálos, aprimorou a habilidade expressar as ideias dentro do processo, de uma forma mais simples e natural. Com a experiência foi possível descobrir um novo olhar para a vida, acessar o outro e a si próprio. A entrega à vulnerabilidade e ao risco da exposição foram ampliados. Diálogos foram incentivados e mesclados pelo silêncio, trazendo à tona as questões importantes debatidas no Refúgio Criativo. Outros desdobramentos subjetivos foram estruturados por nós em tópicos: 'sobre as fronteiras entre Arquitetura e Design'; 'sobre o uso do desenho', 'sobre atitudes inter e intrapessoais e os processos de colaboração/ participação', 'o resgate da criatividade pessoal e da atenção'. Em uma síntese produzida ao fim do workshop definimos a experiência como 'o Refúgio foi construído dentro de cada um de nós' (Figura 14). 
Figura 14 - Representação do significado do Refúgio Criativo para o grupo

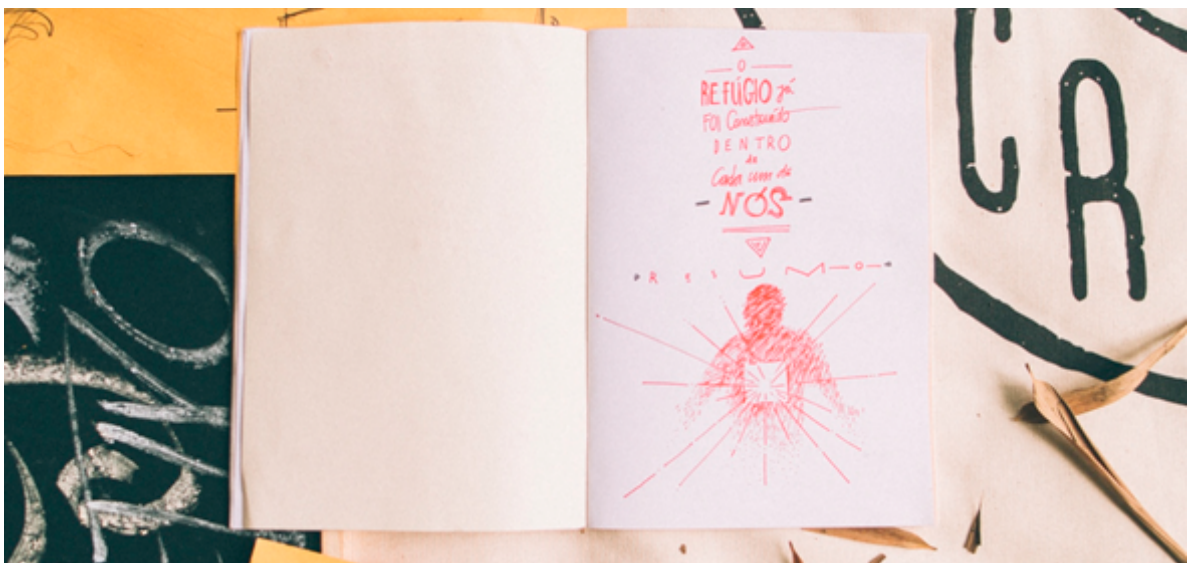

Fonte: Entremonte (estúdio de fotografia e vídeo)

Já os desdobramentos objetivos estruturamos nos seguintes tópicos: 'sobre as afinidades entre Arquitetura e Design para o projeto da cabana'; 'sobre a identidade do Refúgio Criativo', 'sobre textos e depoimentos pessoais', sobre as estratégias de disseminação de conteúdo', sobre as imagens do registro', 'sobre outras mídias impressas ou digitais', sobre o site do Refúgio Criativo', 'sobre o ponto de vista pessoal e profissional das empresas participantes do workshop'.

Os reflexos do Refúgio Criativo na Metroquadrado tonaramse mais evidentes nos meses subsequentes à realização do refúgio. Desde então, uma série de reuniões informais e workshops internos da equipe do escritório foram realizados. Ao mesmo tempo, paralelamente e de forma fluida e orgânica, ocorreram uma série de ações externas ao dia a dia do escritório, que reuniam representantes daliderança da Metroquadradoe alguns profissionais participantes do Refúgio Criativo, fundamentalmente os sócios do estúdio Firmorama. Basicamente, tratou-se de encontros que tiveram como objetivo dar 
continuidade às reflexões oriundas daquele experimento imersivo, procurando elucidar novos rumos para ambas as empresas, com base nos cruzamentos entre a realidade (e limitações) das empresas e as atividades teóricas e práticas de imersão do workshop Refúgio Criativo, principalmente evidenciando os pontos de contato entre arquitetura e design nos processos de cada empresa. 


\section{REFERÊNCIAS}

ABELLÁN, M.; AGREST, D. Ephemeral. Barcelona, Monsa, 2014.

BISELLI, Mario. Teoria e prática do partido arquitetônico. Disponível em: <http://www.vitruvius.com.br/revistas/read/ arquitextos/12.134/3974>. Acesso em: 11 jul. 2014.

BROWN, T. Design Thinking: uma metodologia poderosa para decretar o fim das velhas ideias. 3. ed. Rio de Janeiro: Elsevier, 2010.

CROSS, N. Desenhante: o pensador do desenho. Santa Maria: SCHDs. 2004.

DORNBURG, J. S. Arte y arquitectura: nuevas afinidades. Barcelona: Gustavo Gili, 2002.

FIRMORAMA. Disponível em: <http://www.firmorama.com/sobre>. Acesso em: 09 mar. 2015.

GOMES, L. V. Criatividade: projeto, desenho, produto. Santa Maria: sCHDs, 2001.

KAHN, L. I. How Im Doing, Corbusier. (1972). In: LATOUR. Alessandra (ed.). Louis I Kahn. Writings, Lectures, Interviews. Nova lorque: Rizzoli, 1991, pp. 297-312.

. The Profession and Education, In: WURMAN, Richard Saul. What Will Be has Always been. Nova lorque: Rizzoli, 1986, p.92.

. Signature Against the Sky (1967). In: Eye on Art "Signature agaist the sky", a portrait of Louis I. Kahn, architect. produção de WCAU-TV Philadelphia. 
. Forma e design. ( $1^{\circ}$ ed.). Tradução: Raquel Peev. 1. ed.São Paulo: Martins Fontes, 2010.

MAHFUZ, E. Reflexões sobre a construção da forma pertinente. Disponível em: <http://www.vitruvius.com.br/revistas/read/ arquitextos/04.045/606>. Acesso em: 11 juL. 2014.

Arquitetura é Arte? Revista Summa, Buenos Aires, n. 134, p. 128, mar. 2014.

MEDEIROS, L. M. S. Desenhística: a ciência da Arte de projetar desenhando. Santa Maria: sCHDs, 2004.

NACCACHE, A. (Org.). Criatividade brasileira. Barueri: Manole, 2013.

OSTROWER, F. Criatividade e processos de criação. Petrópolis: Vozes, 2013.

PALLASMAA, J. Os olhos da pele: arquitetura e os sentidos. 2. ed. Londres: Academy Press, 2005.

PIRONDI, C. Um desenho sobre as incertezas. Revista Móbile, São Paulo: CAU/SP, n. 1, p. 29, jun. 2014.

RONNER, H.; JHAVERI, S.; VASELLA, A. Louis I. Kahn: complete works, 1935-1974. Basel: Birkhäuser, 1977.

SANTA ROSA, J. G.; MORAES, Anamaria de. Design participativo. 1. ed. Rio de Janeiro: Rio Books, 2012.

SEGAWA, H. Saberes e fazeres na arquitetura. Revista Móbile, São Paulo: CAU/SP, n. 1, p. 28, jun. 2014.

SANDERS, E. B.; BRANDT, E.; BINDER, T. A framework for organizing the tools and techniques of Participatory Design. Sydney, Austrália: Artigo, 2010. 
SANDERS, E. B. From user-centered to participatory design approaches. In: FRACARA, J. [colocar o nome por extenso] (Ed.). Design and the social sciences. [local de publicação]: Taylor \& Francis Books Limited, 2002. Disponível em: <http://maketools.com/articlespapers/FromUsercenteredtoParticipatory_Sanders_\%2002.pdf >. Acesso em: 10 dez. 2014.

Prototyping for the design spaces of the future. 2013. Disponível em: <http://www.maketools.com/articles-papers/ Sanders2013Prototyping.pdf>. Acesso em: 05 out. 2014.

.Information, inspiration and co-criation. In: CONFERENCE OF THEEUROPEANACADEMYOFDESIGN,6.,2005,Alemanha:Universidade de Artes de Bremen, 2005. Disponível em: <http://www.maketools. com/articles-papers/InformationInspirationandCocreation_ Sanders_05.pdf>. Acesso em: 16 set. 2014.

SANDERS, E. STAPPERS, P. Co-cration and the new ladscapes of design. In: CoDesign, Taylor \& Francis, 2008. Disponível em: <http:// journalsonline.tandf.co.uk>. Acesso em: 05 out. 2014.

TAVARES FILHO, A. C. Transições entre os planos conceitual e material da concepção arquitetônica em Louis I. Kahn. Disponível em: <http://www.arquiteturarevista.unisinos.br/index. php?e=7\&s=9\&a=46>. Acesso em: 7 jul. 2014.

VIANA, M.; VIANNA, Y.; ADLER, I.; LUCENA, B.; RUSSO B. Design thinking: inovação em negócios. Rio de Janeiro: MJV Press, 2012. 162 p.

ZUMTHOR, P. Pensar a arquitectura. Barcelona: Gustavo Gili, 2009. 
